\title{
The Faculty of Pharmaceutical Medicine
}

The Faculty of Pharmaceutical Medicine of the three Royal Colleges of Physicians of the United Kingdom was inaugurated on the 26th October 1989 and has over 500 pharmaceutical and regulatory physicians in various categories of membership. Pharmaceutical medicine is defined in the standing orders of the Faculty as 'a discipline concerned with the discovery, development, evaluation, and monitoring of medicines and their marketing' (Faculty of Pharmaceutical Medicine, 1989). In keeping with this broad definition, the Faculty has interpreted the membership of the discipline to be those whose full time occupation is dedicated to such activities and who require a comprehensive understanding of all aspects of the subject. Thus the majority of its members are pharmaceutical and regulatory physicians, but, in addition, the Board of the Faculty has conferred Fellowship or Membership by distinction on a small number of other physicians who have made major contributions to aspects of pharmaceutical medicine, some of whom are clinical pharmacologists.

During its first year the Faculty has engaged in the work related to its rapidly growing membership; including setting the syllabus and assessment for new membership requirements, establishing communications systems (the Faculty public relations committee, the Faculty newsletter - three issues per year and the meetings subcommittee), organising the administrative office at the Royal College of Physicians in London and not least the design and construction of the coat of arms (Figure 1). As it enters its second year the Faculty must now direct its attention to its long term objectives in addition to establishing its body of membership.

\section{The role of the Faculty of Pharmaceutical Medicine}

At the Inaugural General Meeting of the Faculty, Dame Margaret Turner-Warwick stated 'Faculties and Colleges

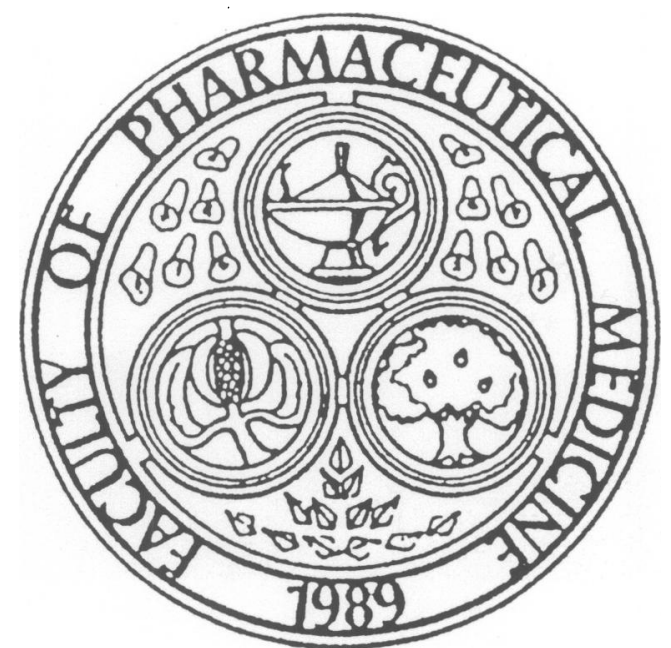

Figure 1 The coat of arms of the Faculty of Pharmaceutical Medicine. are all about standards'. Faculties and Colleges are registered charities and should not exist to benefit individual members or groups of members. The objective of these institutions, as embodied in their standing orders and byelaws, is to raise the standard of medicine such that the public will benefit. Indeed some of the postgraduate activities of the Royal Colleges are devoted to those who are not members of Colleges such as postgraduate doctors as yet to be fully trained. Another activity dedicated to the raising of standards is audit and it is highly appropriate that the Colleges are so active in its implementation. A model widely used in audit is the audit cycle (Royal College of Physicians, 1989) whereby standards are researched and set, then the standards of the group are assessed using a primary bench mark which is later reset to reflect developments in medical knowledge and the rising standards of the group overall. Such a model could be applied to the objectives of the Faculty and may help to outline a plan to achieve them.

\section{Setting standards and the syllabus}

The Faculty of Pharmaceutical Medicine must first research and then set standards. This undertaking requires definition of the breadth and depth of the subject which is a considerable challenge to an apparently disparate group of pharmaceutical and regulatory physicians. It is compounded by the discipline's rapid development leading to few relevant textbooks on the subject. Following the model of other Colleges and Faculties the standards required for the first part of membership (Associateship) should concentrate on the core knowledge required and the second part of membership (Membership) on its practical application. The subject matter and the required level of knowledge of this have been proposed for both Associateship and Membership and are based on an extension of the existing syllabus for the Diploma of Pharmaceutical Medicine.

\section{Assessment, examination and training}

Once standards are formally set - the 'syllabus' - a system of assessment has to be constructed whereby performance can be measured. Although the Faculty itself is anxious that training and education to the right standard is available, like other Faculties and Colleges it will not be directly involved in conducting that training which will be undertaken by specialist courses. To foster the understanding of the syllabus for Associateship and Membership the Faculty will have supervisors for the individual candidates and will provide further information to those participating in and conducting the training. The format for assessment is evolving and the Faculty is facing the problem that there are insufficient validated 
assessment questions in pharmaceutical medicine because of the rapid development of the discipline. However the 15 year experience of the annual written and oral examination in the Diploma of Pharmaceutical Medicine provides a solid foundation for this exercise. Whilst clear instructions and plenty of support for each cohort of candidates must be given, examination procedures will be constantly under review and will have to be as flexible as possible to enable the most effective discriminating assessment system to emerge.

In addition to setting standards and assessment procedures for Membership requirements, the Faculty must also set standards for physicians not members of the discipline. It is here in both undergraduate and postgraduate settings that the clinical pharmacologist members of the Faculty fulfil an extremely important role enabling us to have links with universities otherwise not available. Hopefully in the future such links may be established, possibly through a formalised system of honorary appointments of pharmaceutical physicians to clinical pharmacology departments. A subcommittee of the Faculty, including those with appointments in clinical pharmacology, has been formed to review such issues.

The Faculty is also involved in other standard raising activities such as development of clinical research audit a rapidly growing subject in medicine. The approach taken in pharmaceutical medicine is different from that required in clinical medicine by the government white paper (Working for Patients, HMSO 1989), the Faculty intends to collaborate with other groups who may be considering audit in clinical therapeutic research to ensure quality is raised in the most effective way.

\section{Continuing education}

The Faculty has also planned a programme of two academic meetings per year. One in London on the day of the Annual General Meeting, the other either in Glasgow or Edinburgh. Thus at the Annual General Meeting on December 10th 1990 there was one hour of submitted papers followed by an Oxford style debate on 'Scientific and ethical standards in pharmaceutical medicine should be self regulated'. An all day meeting has successfully taken place on 'Pharmaceutical Medicine and the Law' on Tuesday 23rd April 1991 at the Royal College of Physicians and Surgeons in Glasgow. The proceedings of this meeting are to be published in book form by the Royal College of Physicians, London. These meetings are intended to facilitate the presentation of scientific papers and also highlight important subjects of topical interest.

\section{Completion of the cycle}

To complete the cycle the Faculty must constantly review issues within pharmaceutical medicine ensuring that the syllabus and assessment techniques are appropriately modified and new standards are communicated throughout the medical profession in continuing education. As standards constantly improve so indeed will the prestige of pharmaceutical medicine as a respected discipline.

\author{
F. J. GABBAY ${ }^{1}$ \& A. GOLDBERG ${ }^{2}$ \\ ${ }^{1}$ Dickson Gabbay Limited, 5 Manor Court, \\ Barnes Wallis Road, Segensworth East, Fareham, \\ Hampshire, PO15 5TH \\ ${ }^{2}$ Faculty of Pharmaceutical Medicine, \\ 6 St Andrews Place, Regents Park, \\ London NW1 4LB
}

\section{References}

Faculty of Pharmaceutical Medicine of the Royal Colleges of Physicians of the United Kingdom. (1989). Faculty Standing Orders.

HMSO. (1989). Working for Patients. London: HMSO.
Royal College of Physicians. (1989). Medical audit: A first report. What, why and how? London: Royal College of Physicians. 